\title{
EFFECT OF GARLIC AND ATORVASTATIN ON LEPTIN AND LIPID PROFILE IN TRITON X-100 INDUCED HYPERLIPIDEMIA IN RATS
}

\author{
Nabil M. Tahal , Hatem S. Abdel-Hamid ${ }^{2}$, Kadry M. Sadek, \\ Ahmed Z. Abdalaziz \\ ${ }^{1}$ Department of Biochemistry, Faculty of Veterinary Medicine, \\ Alexandria University, Egypt. \\ ${ }^{2}$ Department of poultry diseases, Faculty of Veterinary Medicine, \\ Damanhur University, Egypt. \\ ${ }^{3}$ Department of Biochemistry, Faculty of Veterinary Medicine, \\ Damanhur University, Egypt.
}

\begin{abstract}
Hyperlipidemia is widely known to be the major risk factor for the development of cardiovascular diseases. This study was conducted to determine the effect of Garlic on Leptin hormone and Lipid Profile in Triton $x-100$ induced hyperlipidemic rats compared with standard hypolipidemic Atorvastatin. A total number of 60 albino rats were allocated into six equal groups, 10 rats each. The first group was kept on Standard pellet diet (served as normal control), the second group was kept on $1 \%$ garlic added to standard pellet diet, the third group was administered with standard Atorvastatin $10 \mathrm{mg} / \mathrm{kg}$ p.o. daily (served as standard), the forth group was given a single dose of triton at a dose $100 \mathrm{mg} / \mathrm{kg}$ and repeated every two weeks, i.p. (served as Triton control), fifth and sixth groups were given a single dose of triton at a dose $100 \mathrm{mg} / \mathrm{kg}$ and repeated every two weeks, i.p. and the fifth group was given garlic $1 \%$ added to standard pellet diet while sixth group was administered with standard Atorvastatin $10 \mathrm{mg} / \mathrm{kg}$
\end{abstract}


p.o. (served as treated groups), after inducing hyperlipidemia (for 6 weeks). Results showed that, garlic significantly decreased cholesterol, LDL-C, VLDL-C and TG and significantly increased HDL compared with triton $x$-100 -treated group. On the other hand, there were a non significant differences in total lipid, phospholipids and leptin levels compared with triton $x$-100 -treated group. We concluded that, Garlic has definite antihyperlipidemic activity in Triton X-100 induced hyperlipidemia model which is equipotent activity when compared with Atorvastatin. This might returned in addition to its own hypolipidemc activity to increased leptin sensitivity in hypothalamus. Further studies on Garlic needed to identify the possible mechanism of action on leptin hormone.

Keywords: Atorvastatin, garlic, hyperlipidemia, leptin, Triton x-100.

\section{INTRODUCTION}

Current predictions estimate that by the year 2020 cardiovascular diseases, notably atherosclerosis, will become the leading global cause of total disease burden (Kaur, 2006). The same study speculated that, an important factor for atherosclerosis is hyperlipidemia. Hyperlipidemia is the presence of raised or abnormal levels of lipids and/or lipoproteins in the blood (Frederickson and Lee, 2006). It is also synonymously known as dyslipidemia (Chen, 2005). During the past decade, a vast amount of evidence has confirmed the critical role played by the dyslipidemias in the pathogenesis of atherosclerosis and coronary artery disease (Vega and Sirtori, 1996). The advantages of lowering lipid levels to satisfactory levels have been confirmed by several experimental and interventional studies indicating lower morbidity and mortality in coronary heart disease which commensurate with reduction of serum 
cholesterol (Jackson and Beagle, 1995). Garlic (Allium sativum L.) possesses many healthful properties that are related to its bioactive compounds (Leelarungrayub et al., 2006, Arnault and Auger, 2006, Okada et al., 2005 and Lee et al., 2005). It was reported that, consumption of garlic is very helpful in regulating plasma lipid levels (Lau, 2006) as well as plasma anticoagulant activity (Pierre et al., 2005, Lawson et al., 1992) and in prevention of the atherosclerosis process (Rahman and Lowe, 2006) and even cancer (Velmurugan and Nagini, 2005). It was shown that, garlic also provides protection against ethanol induced gastric injury (Khosla et al., 2004). The most studied and reported health-promoting effect of garlic is cardioprotection ( $\mathbf{L a u}, \mathbf{2 0 0 6}$, Rahman and Lowe, 2006). However, a pilot study of garlic consumption shows no significant effect on markers of oxidation or subfraction composition of low-density lipoprotein (LDL-C) (Byrne et al., 1999). There is no doubt that, garlic and garlic preparations possess anticoagulant abilities (Pierre et al., 2005, Lawson et al., 1992). Garlic has been proposed to have direct anti-atherogenic (preventive) and antiatherosclerotic (causing regression) effects at the artery wall (Sukandar et al., 2010). Adipocytes cells secrete a protein hormone called leptin in proportion to the amount of triglycerides they have stored (Isganaitis and Lustig, 2005). Thus, in a long term, excess ingestion of calories resulting in increased fat deposition triggers an increase in leptin secretion. Leptin impinges on its receptors in the hypothalamus to alter the set point at which satiety is reached, so that the individual eats less due to loss of appetite and, hence, assimilates fewer calories (Isganaitis and Lustig, 2005, Mcphee et al., 2006). Although leptin is a circulating signal that reduces appetite, obese people generally have an unusually 
high circulating concentration of leptin. Obese individuals are therefore resistant to the effect of leptin due to low sensitivity of the hypothalamus to leptin (Considine et al., 1996). Although, some researchers have proved that regular addition of garlic to diet can help reduce blood cholesterol and glucose levels (Drobiova et al., 2009, Mahesaret al, 2010, Liuet al., 2007), there is still a controversy regarding the plasma lipid regulating and antioxidant increasing properties of garlic. Therefore, it was decided to study the possible changes in the plasma lipid levels and leptin hormone through an experiment on Triton x-100 hyperlipidemic rats in comparison with standard hypolipidemic atorvastatin.

\section{MATERIAL AND METHODS}

\section{Chemicals:}

Atorvastatin was obtained from market $\left(\right.$ LIPINORM $\left.^{\circledR}\right)$ Batch number: 11227. Triton X-100(a non-ionic detergent, iso octyl polyoxy ethylene phenol, formaldehyde polymer) was obtained from Sigma Aldrich. Cholesterol kit (Colorimetric Method), HDL-C kit, Triglycerides, LDL-C and Phospholipids kits were purchased from Biodiagnostic and Bilirubin, ALT activity and AST activity kits used were of analytical grade.

\section{Plant material:}

The fresh garlic-Allium sativum- was obtained from the local market. Dried and ground bulbs. It was mixed with basal diet as $1 \%$ mixture. 
Animals:

This study was carried out at the faculty of Veterinary Medicine, Damanhur University using 60 male albino rats weighing 130-200g and 3.5-4 months old. Rats were housed in clean disinfected floor in wooden cages. Food and water were available ad libitum. They were housed in a room where the congenial temperature was $27^{\circ} \mathrm{C} \pm 2^{\circ} \mathrm{C}$ and nearly $12 \mathrm{hr}$ light and dark cycles were maintained. The animals were allowed to acclimatize to the environment for 10 days and supplied with a standard pellet diet and water ad libitum.

\section{Induction of hyperlipidemia:}

Hyperlipidemia was induced in albino rats by intraperitoneal injections of freshly prepared solution of Triton-X-100 $(100 \mathrm{mg} / \mathrm{kg})$ in physiological saline after overnight fasting for 18 hours every 2 weeks 3 times from beginning of experiment (Mohale et al., 2008, Ansarullah et al., 2009).

\section{Experimental design:}

A total number of 60 albino rats were allocated into six equal groups, 10 rats per group as follow:

The first group was given Standard pellet diet (Served as normal control) [G1]. The second group was given $1 \%$ garlic added to standard pellet diet[G2], Third group was administered with Standard Atorvastatin $10 \mathrm{mg} / \mathrm{kg}$ p.o. daily (served as standard) [G3]. The forth group was given a single dose of triton at a dose $100 \mathrm{mg} / \mathrm{kg}$ and repeated every two weeks, i.p. (Served as Triton control) [G4]. Fifth and sixth group was 
given a single dose of triton at a dose $100 \mathrm{mg} / \mathrm{kg}$ and repeated every two weeks, i.p. and the fifth group was given garlic $1 \%$ added to standard pellet diet[G5] while sixth group was administered with Standard Atorvastatin $10 \mathrm{mg} / \mathrm{kg}$ p.o. [G6] (served as treatment groups), after inducing hyperlipidemia.

\section{Collection of blood samples:}

After six weeks of treatment, the blood was collected by retro orbital sinus puncture, under mild ether anesthesia in plane tubes. Serum obtained by immediate centrifugation of blood samples at $4000 \mathrm{rpm}$ for 10 minutes at room temperature and was directly used for estimating serum lipid profiles (serum TC, TG, LDL-C and HDL-C). All samples were stored at $-80^{\circ} \mathrm{C}$ until analysis.

\section{Biochemical analysis:}

Serum lipid levels include TC, TG and HDL-C, LDL-C, were carried out using respective diagnostic commercial kits from Biodiagnostics, Egypt and VLDL was calculated as friedewald estimation (Friedewald et al., 1972), LDL-C $=$ (TC-(TG/5+HDL)-C) $\mathrm{mg} / \mathrm{dl}, \mathrm{VLDL}=(\mathrm{TG} / 5)$.

- Leptin was determined using commercial ELISA kits method

\section{- Leptin Kit}

- RayBio ${ }^{\circledR}$ Rat Leptin ELISA Kit Protocol; (Cat\#: ELR-Leptin-001); RayBio® ELISA kits: www.raybiotech.com, It was imported by Sigma Scientific Services Co., Egypt. 


\section{Statistical analysis:}

The data of Triglycerides, Cholesterol, HDL, LDL, VLDL, Total Lipids, AST activity, ALT activity, Leptin, Bilirubin and Phospholipids at 6 weeks were analyzed by Statistical Package for the Social Sciences (SPSS Inc., 2011). One way analysis of variance ANOVA with the following model:

$$
\mathbf{Y q j}=\mu+\alpha \mathbf{q}+\text { eqj }
$$

\section{Where:}

Yqj $=$ an observational data $\mathbf{q}=1,2,3,4,5$ and $6(1=\mathrm{G} 1,2=\mathrm{G} 2,3=\mathrm{G} 3$, $4=\mathrm{G} 4,5=\mathrm{G} 4$ and $6=\mathrm{G} 6)$.

$\mathbf{A q}=$ group effects

eqj $=$ random error.

\section{RESULTS AND DISCUSSION}

Coronary heart diseases, stroke, atherosclerosis and hyperlipidemia are the primary cause of death (Grundy, 1986, Davey, 1993). Therefore, prime consideration in the therapy for hyperlipidemia and arteriosclerosis is to attenuate the elevated blood serum/plasma levels of lipids. The currently available antihyperlipidemic therapy includes mainly HMGCoA reductase inhibitors (Statins), Bile acid sequesterants (Resins), Activate lipoprotein lipase (Fibric acid derivatives), Inhibit triglyceride synthesis (Nicotinic acid) and others (Gugulipid, Ezetimibe, Policosanol) (Brown et al., 1993). Though there are a large number of antihyperlipidemic agents used in the treatment, none of the existing one available worldwide are fully effective, absolutely safe and free from side effects (Ghatak and Asthana, 1995). So efforts are being made to

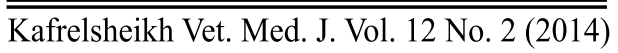


find out safe and effective agents that may be beneficial in correcting the lipid metabolism and preventing cardiac diseases. Many herbs and plant products have been shown to have antihyperglycaemic and antihyperlipidemic properties (Brown et al., 1993). The use of herbs and other natural products has gained popularity, and the increase in their consumption is backed by solid scientific evidence (Pierre et al., 2005, Ramaa et al., 2006, Slekovec and Goessler, 2005). One of these natural products is garlic, which has been used throughout the history of civilization for treatment of a wide variety of ailments (Leelarungrayub et al., 2006, Arnault and Auger, 2006, Okada et al., 2005, Lee et al., 2005). The wide range of ailments in which this vegetable is used (Lawson et al., 1992, Velmurugan and Nagini, 2005, Khosla et al., 2004) could create an impression that garlic is a panacea, but it is not (Byrne et al., 1999, Kerckhoffs et al., 2002). The most studied and reported health promoting effect of garlic is cardioprotection ( $\mathbf{L a u}, \mathbf{2 0 0 6}$, Rahman and Lowe, 2006). Therefore, this investigation was to study the influence of garlic on lipid profile and leptin on Triton x-100 induced hyperlipidemic rats. The results of present study are given in Table (1). The rats treated with triton showed significant increase in serum cholesterol level from $146.80 \mathrm{mg} / \mathrm{dl}$ in normal rats to $197.50 \mathrm{mg} / \mathrm{dl}$, triglyceride level from $67.37 \pm 4.63 \mathrm{mg} / \mathrm{dl}$ in normal rats to $100.72 \pm 2.90$ $\mathrm{mg} / \mathrm{dl}$ and LDL-C from $110.40 \pm 3.20 \mathrm{mg} / \mathrm{dl}$ in normal rats to $158.10 \pm 3.12$ $\mathrm{mg} / \mathrm{dl}$. An increased risk of coronary heart disease is associated with a high serum concentration of total cholesterol, LDL and triglyceride (Sheehan and Jensen, 2000). Treatment with Garlic and Atorvastatin reduced the serum TC, TG \& LDL-C levels when compared to the 
hyperlipidemic control group. Garlic and Atorvastatin showed a decrease in the levels of cholesterol, Triglyceride, and LDL-C level. Administration of Garlic in triton induced hyperlipidemic rats decrease the cholesterol level to $170.70 \pm 4.23 \mathrm{mg} / \mathrm{dl}$, triglyceride level is $80.26 \pm 2.06 \mathrm{mg} / \mathrm{dl}$ and HDL-C level is $22.87 \pm 1.91 \mathrm{mg} / \mathrm{dl}$ as compare to standard drug Atorvastatin where decrease of cholesterol level is by $158.40 \pm 5.57 \mathrm{mg} / \mathrm{dl}$ triglyceride level is by $76.51 \pm 1.91 \mathrm{mg} / \mathrm{dl}$ and HDL-C level is $21.13 \pm 1.48 \mathrm{mg} / \mathrm{dl}$ in triton induced hyperlipidemic rats. Diets supplemented with garlic not significantly decreased the total lipid levels and not significantly increased serum leptin and phospholipids levels (P $>$.05) compared with triton $\mathrm{x}-100$ treated group. The increase in HDL-C level may be due to the activity of LCAT and inhibition of the action of hepatic TG-lipase on HDL, which may contribute for rapid catabolism of blood lipids through extra hepatic tissues (Gordon et al., 1989). The same authors revealed that, it is widely accepted that elevation in plasma HDL-C level decreased the risk factor for developing atherosclerosis, by increasing the clearance of cholesterol from the arterial wall. Garlic may have served other systemic and cardiovascular functions such as antithrombotic, antibiotic, antiglycative, anti-inflammatory, hypolipidemic, hypo-cholesteremic, anti-atherosclerotic, hypoglycemic and hypotensive activities, rather than reducing weight significantly in the normal rats and mice (Drobiova et al., 2009, Mahesaret al., 2010, Liuet al., 2007). The possible mechanisms of garlic as lipid lowering agent are its inhibitory effect on hepatic activities of lipogenic and cholesterogenic enzymes such as malic enzyme, fatty acid synthase, glucose- 6 phosphate dehydrogenase and 3-hydroxy-3-methyl-glutaryl-CoA (HMG CoA) 
reductase (Sukandar et al., 2010). It was also suggested that garlic lowers serum lipids by delaying lipid absorption from gastrointestinal tract and diminishing LDL cholesterol synthesis in the liver. Garlic also increases the body's metabolic rate by stimulating the adrenal gland to release adrenaline which increases the rate of fat metabolism in the body and in turn helps burn more calories to decrease weight (Noaki et al., 2007). Garlic actions related to lipid metabolism is probably due to the action of allicin, a potent compound in crushed garlic that increases the body's metabolic rate by stimulating the adrenal gland to release adrenaline which increases the rate of fat metabolism in the body and in turn helps burn more calories and decrease weight (Noaki et al., 2007). The significant hypolipidemic activity observed in group 5 may also be due to the fact that, sulphur-containing compounds in garlic acted on the hypothalamus of the rat, increasing the sensitivity of the hypo-thalamus to leptin, a hormone secreted by fat cells in the body, which functions by impinging its receptors in the hypothalamus altering the set point at which satiety is reached, so that the organism eats less (Mahesar et al., 2010). The hypoglycemic effect may be due to the presence of flavonoids and sulphur-containing compounds in the garlic extract (Mahesar et al., 2010). Garlic may potentiate insulin effect on plasma by increasing secretion of insulin from beta cells of the pancreas (Sukandar et al., 2010). This elevated insulin level causes a decrease in blood glucose. Allicin, the principal bioactive compound in garlic extract also has a scavenging effect on excess glucose stored as fat. Some of the excess glucose is also converted to ATP (Sukandar et al., 201)].This might increase the sensitivity of leptin. Concerning the effect of garlic in 
combination with triton $\mathrm{x}-100$ on liver functions. Table (2) revealed that, the administration of garlic was resulted in decrease in activity of transaminases in serum and Bilirubin level compared with triton x-100 group. These come in agreement with those obtained by Hattori et al., (2001) and Sumioka et al., (2001) who reported that, Ajoene (a garlicderived sulfur-containing compound) and S-allylmercaptocysteine suppressed the rise in serum ALT activity in mice. In the contrary, the present findings disagree with those obtained by Joseph et al., (1989) who reported significant rise in serum AST in rats fed garlic extract. Moreover, Ilker et al., (2004) found that, there were no differences in ALT activity and AST activity when a total of 23 volunteer kept on high cholesterol diet and ingested garlic extract at the dose (10 g garlic/day) for 4 months.

Table (1): Means \pm standard error of Cholesterol, Triglycerides, HDL-C, LDLC, VLDL-C and Total Lipids levels at 6 weeks.

\begin{tabular}{|c|c|c|c|c|c|c|}
\hline $\begin{array}{l}\text { Criteria } \\
\text { Groups }\end{array}$ & $\begin{array}{c}\text { Triglycerides } \\
\text { (mg/dl) }\end{array}$ & $\begin{array}{c}\text { Cholesterol } \\
\text { (mg/dl) }\end{array}$ & $\begin{array}{l}\text { HDL-C } \\
\text { (mg/dl) }\end{array}$ & $\begin{array}{l}\text { LDL-C } \\
\text { (mg/dl) }\end{array}$ & $\begin{array}{l}\text { VLDL-C } \\
\text { (mg/dl) }\end{array}$ & $\begin{array}{c}\text { Total Lipids } \\
(\mathrm{mg} / \mathrm{dl})\end{array}$ \\
\hline 1 & $67.37 \pm 4.63^{\mathrm{cd}}$ & $146.80 \pm 6.73^{\mathrm{c}}$ & $22.83 \pm 0.62^{b}$ & $110.40 \pm 3.20^{\mathrm{c}}$ & $13.47 \pm 0.92^{\text {cd }}$ & $0.97 \pm 0.14^{\mathrm{ab}}$ \\
\hline 2 & $69.84 \pm 4.42^{\text {cd }}$ & $128.70 \pm 5.01^{\mathrm{d}}$ & $31.07 \pm 1.30^{\mathrm{a}}$ & $83.60 \pm 1.72^{\mathrm{d}}$ & $13.97 \pm 0.89^{\mathrm{cd}}$ & $0.90 \pm 0.14^{\mathrm{b}}$ \\
\hline 3 & $64.86 \pm 1.45^{\mathrm{d}}$ & $114.40 \pm 5.13^{\mathrm{d}}$ & $28.73 \pm 1.09^{\mathrm{a}}$ & $72.60 \pm 2.88^{\mathrm{d}}$ & $12.97 \pm 0.29^{\mathrm{d}}$ & $0.99 \pm 0.15^{\mathrm{ab}}$ \\
\hline 4 & $100.72 \pm 2.90^{\mathrm{a}}$ & $197.50 \pm 4.41^{\mathrm{a}}$ & $19.23 \pm 2.07^{b}$ & $158.10 \pm 3.12^{\mathrm{a}}$ & $20.15 \pm 0.58^{\mathrm{a}}$ & $1.40 \pm 0.17^{\mathrm{a}}$ \\
\hline 5 & $80.26 \pm 2.06^{\mathrm{b}}$ & $170.70 \pm 4.23^{\mathrm{b}}$ & $27.87 \pm 1.91^{\mathrm{a}}$ & $131.80 \pm 5.11^{\mathrm{b}}$ & $16.05 \pm 0.41^{\mathrm{b}}$ & $1.16 \pm 0.07^{\mathrm{ab}}$ \\
\hline 6 & $76.51 \pm 1.91^{\mathrm{bc}}$ & $158.40 \pm 5.57^{\mathrm{bc}}$ & $28.13 \pm 1.48^{\mathrm{a}}$ & $121.90 \pm 6.06^{\mathrm{b}}$ & $15.30 \pm 0.38^{\mathrm{bc}}$ & $1.27 \pm 0.13^{\mathrm{ab}}$ \\
\hline
\end{tabular}

Number of samples $=10$

Means carry different superscripts are significantly different at $\mathrm{P} \leq 0.05$. 


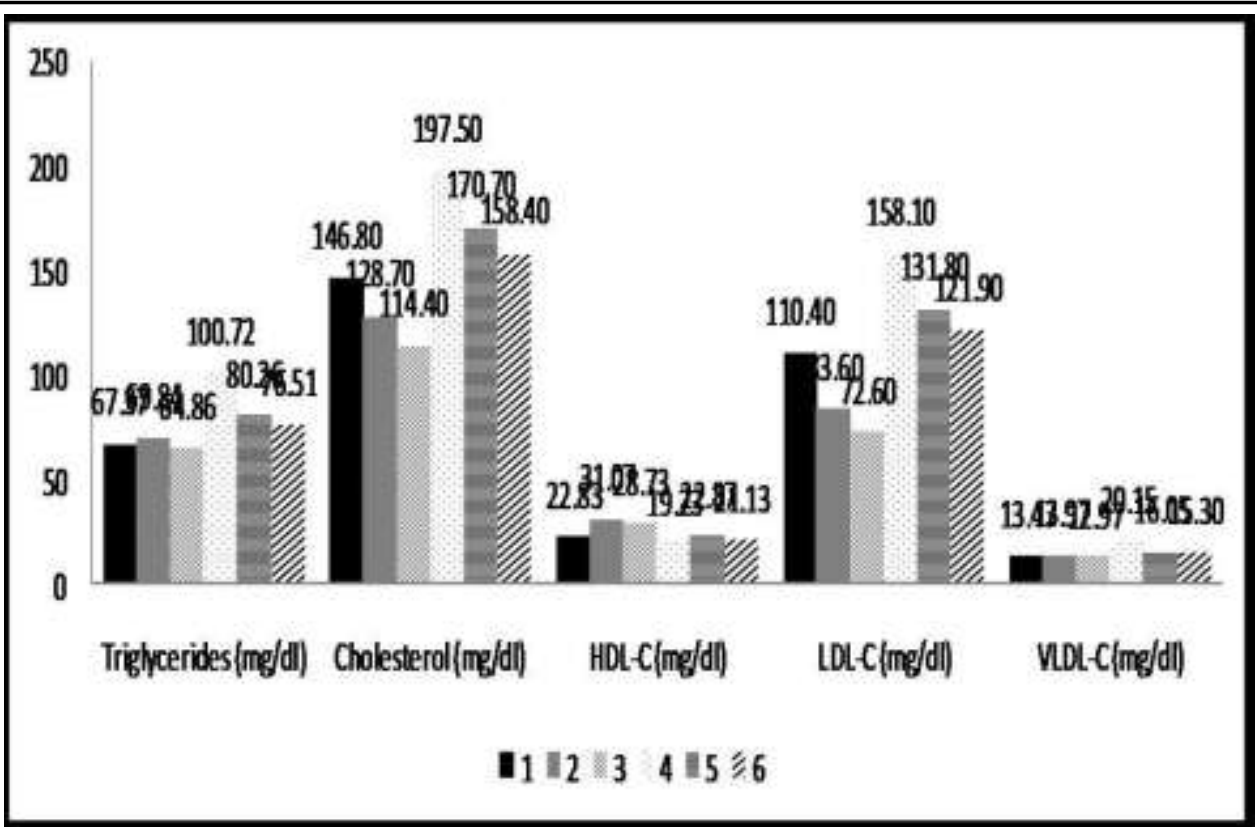

Fig. (1a): Means of Triglycerides, Cholesterol, HDL, LDL and VLDL at 6 weeks.

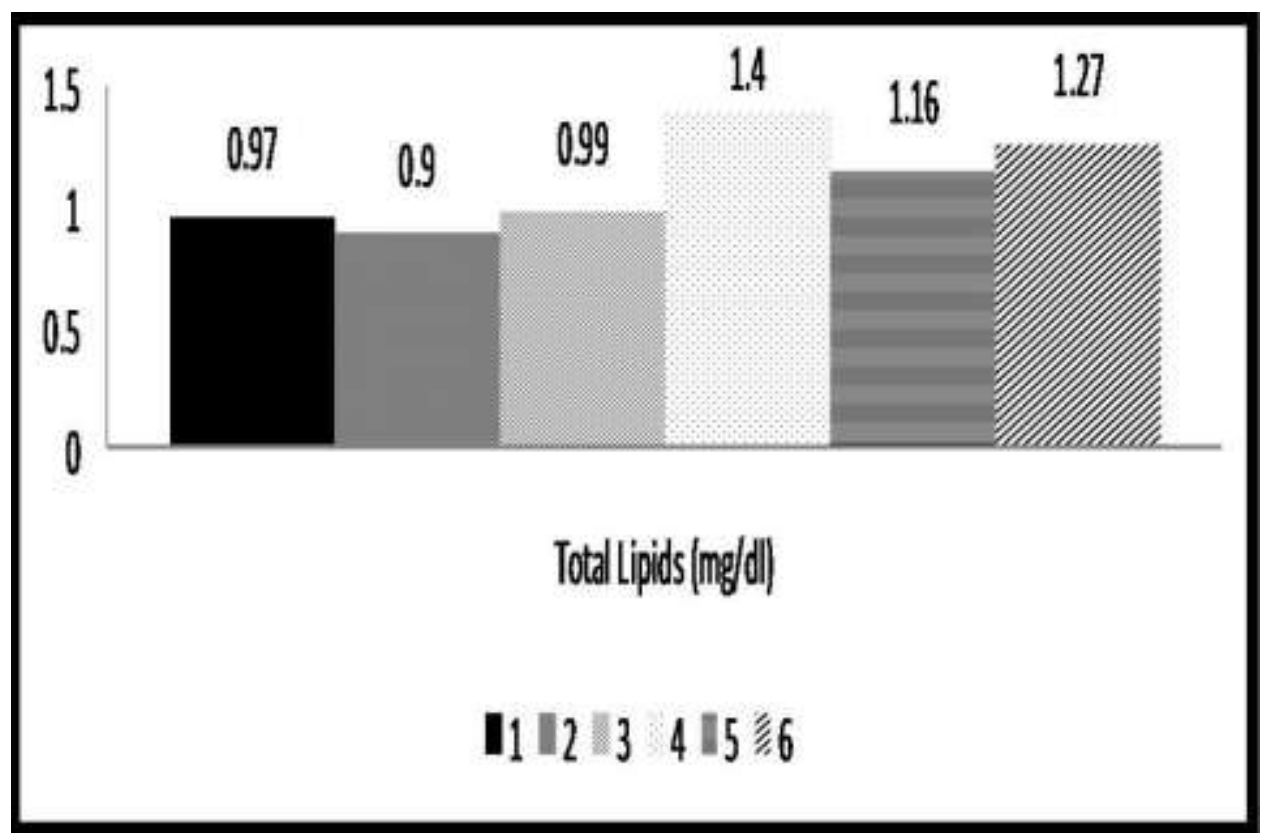

Fig. (1b): Means of Total lipids at 6 weeks. 
Effect Of Garlic And Atorvastatin On Leptin And ...

Table (2): Means \pm standard error of AST, ALT, Leptin, Bilirubin and Phospholipids at 6weeks.

\begin{tabular}{|c|c|c|c|c|c|c|}
\hline $\begin{array}{l}\text { Criteria } \\
\text { Groups }\end{array}$ & $\begin{array}{c}\text { AST } \\
(\mathbf{u} / \mathbf{m l})\end{array}$ & $\begin{array}{c}\text { ALT } \\
(\mathbf{u} / \mathbf{m l})\end{array}$ & $\begin{array}{l}\text { Leptin } \\
(\mathrm{pg} / \mathrm{ml})\end{array}$ & $\begin{array}{c}\text { Bilirubin } \\
\text { (mg/dl) }\end{array}$ & $\begin{array}{c}\text { Phospholipids } \\
\text { (mg/dl) }\end{array}$ & $\begin{array}{l}\text { Criteria } \\
\text { Groups }\end{array}$ \\
\hline 1 & $16.80 \pm 1.27^{\mathrm{b}}$ & $9.80 \pm 0.61^{\mathrm{b}}$ & $6308.40 \pm 407.71^{\mathrm{a}}$ & $0.18 \pm 0.05^{\mathrm{c}}$ & $82.22 \pm 2.32^{\mathrm{c}}$ & $16.80 \pm 1.27^{\mathrm{b}}$ \\
\hline 2 & $13.60 \pm 1.17^{\mathrm{b}}$ & $7.80 \pm 0.70^{\mathrm{b}}$ & $6656.60 \pm 270.41^{\mathrm{a}}$ & $0.19 \pm 0.04^{c}$ & $83.89 \pm 1.80^{\mathrm{c}}$ & $13.60 \pm 1.17^{\mathrm{b}}$ \\
\hline 3 & $13.00 \pm 0.89^{b}$ & $7.70 \pm 0.40^{\mathrm{b}}$ & $5060.10 \pm 539.92^{\mathrm{b}}$ & $0.22 \pm 0.04^{\mathrm{bc}}$ & $78.89 \pm 1.28^{\mathrm{c}}$ & $13.00 \pm 0.89^{\mathrm{b}}$ \\
\hline 4 & $26.30 \pm 2.72^{\mathrm{a}}$ & $13.00 \pm 2.00^{\mathrm{a}}$ & $4136.90 \pm 342.76^{\mathrm{bc}}$ & $0.50 \pm 0.06^{\mathrm{a}}$ & $139.00 \pm 2.88^{\mathrm{a}}$ & $26.30 \pm 2.72^{\mathrm{a}}$ \\
\hline 5 & $14.80 \pm 1.02^{\mathrm{b}}$ & $8.20 \pm 0.61^{\mathrm{b}}$ & $4013.50 \pm 189.80^{\mathrm{bc}}$ & $0.32 \pm 0.02^{\mathrm{b}}$ & $132.00 \pm 2.10^{\mathrm{a}}$ & $14.80 \pm 1.02^{\mathrm{b}}$ \\
\hline 6 & $14.20 \pm 1.36^{\mathrm{b}}$ & $8.40 \pm 0.93^{\mathrm{b}}$ & $3365.50 \pm 325.69^{c}$ & $0.26 \pm 0.03^{b c}$ & $117.56 \pm 3.90^{\mathrm{b}}$ & $14.20 \pm 1.36^{\mathrm{b}}$ \\
\hline
\end{tabular}

Number of samples $=10$

Means carry different superscripts are significantly different $(\mathrm{P} \leq 0.05)$

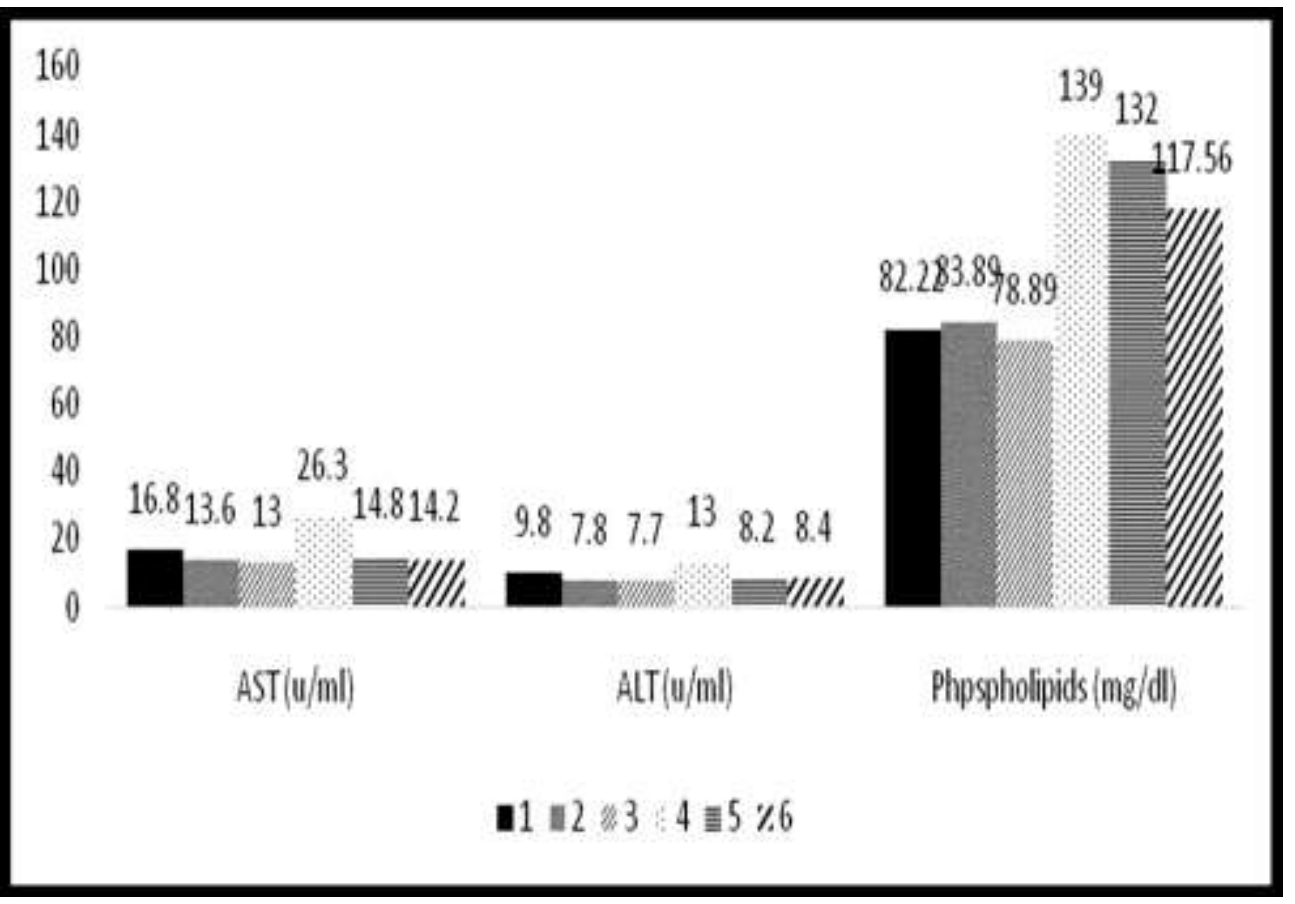

Fig. (2a): Means of AST activity, ALT activity and Phospholipids at 6 weeks.

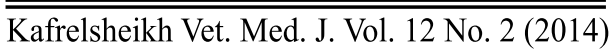




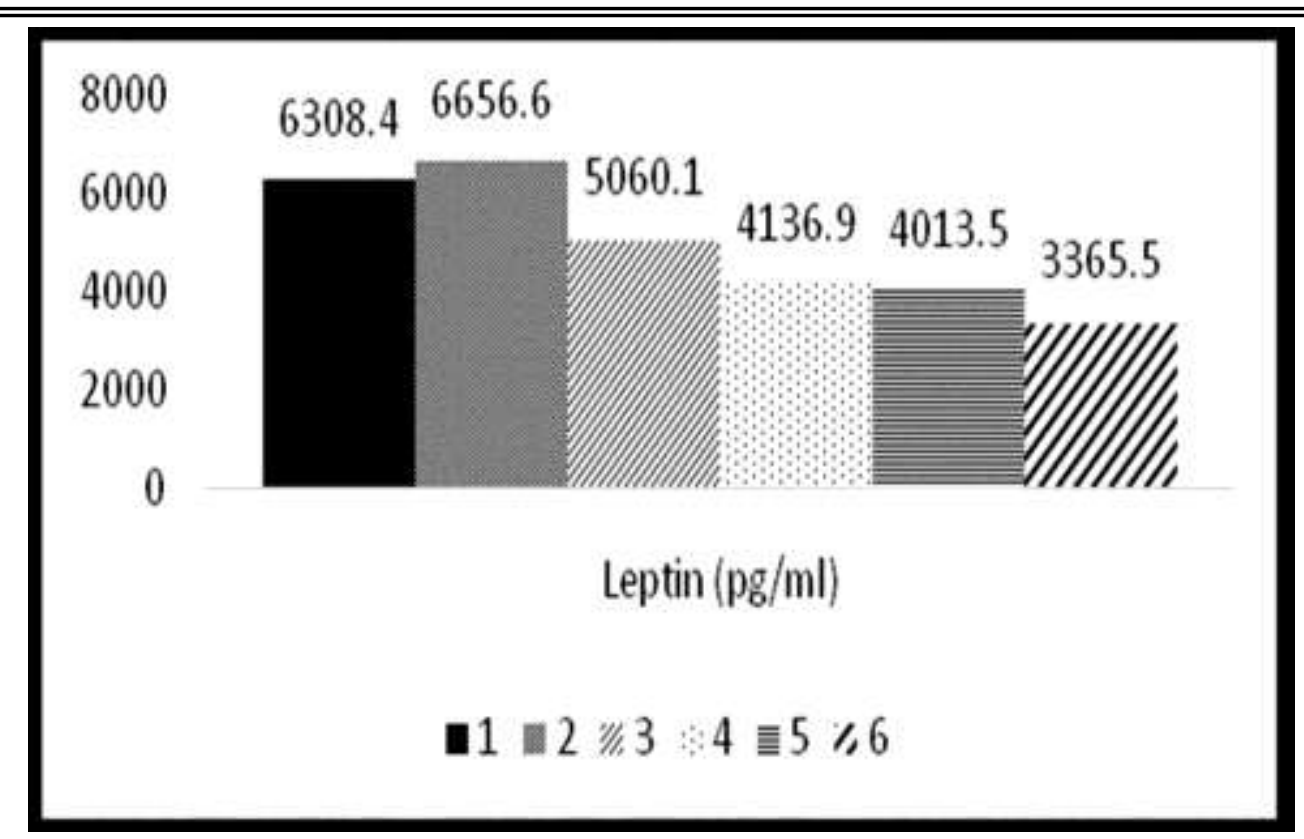

Fig. (2b): Means of Leptin6 weeks.

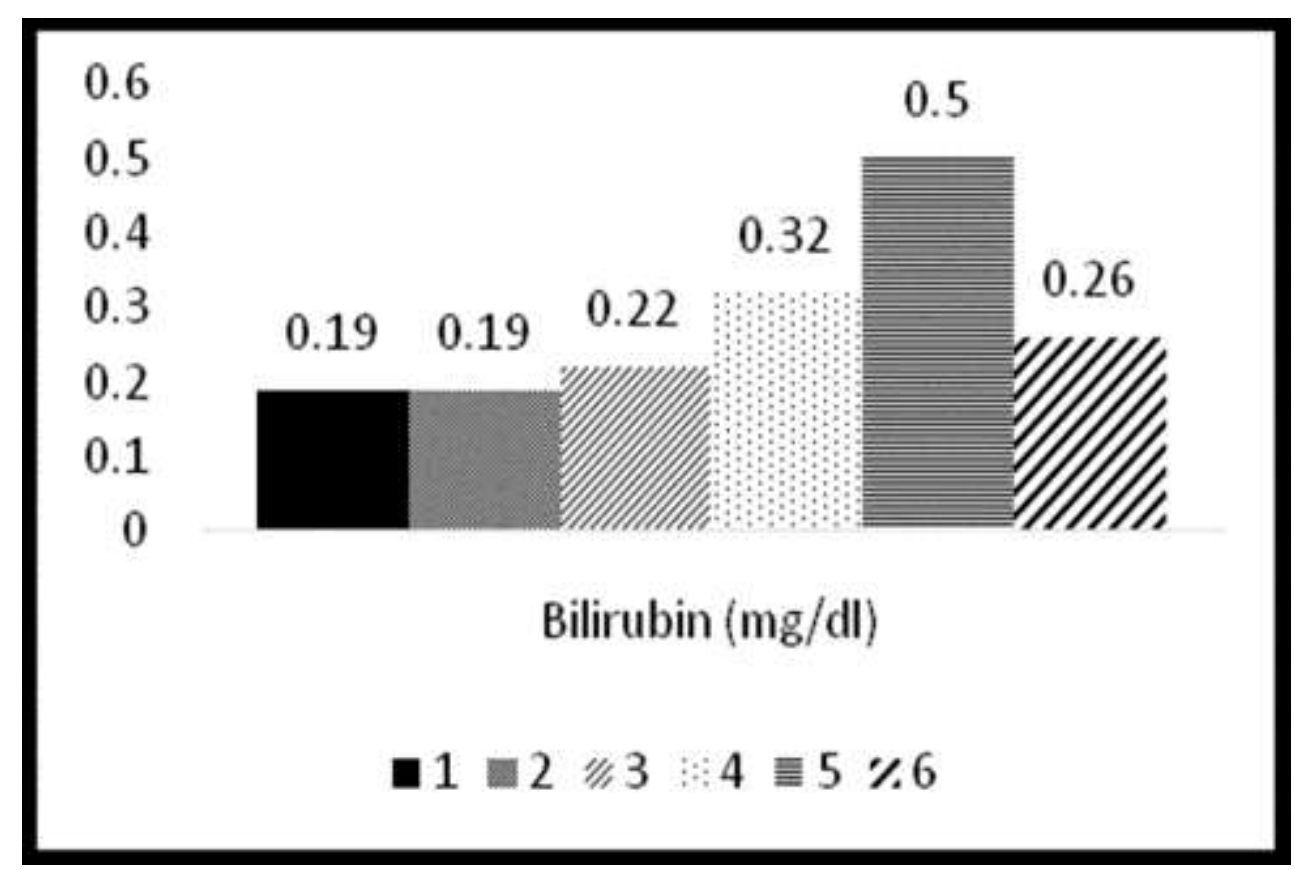

Fig. (2c):Means of Bilirubin6 weeks. 


\section{CONCLUSION}

The results concluded that Garlic has definite antihyperlipidemic activity in Triton X-100 induced hyperlipidemia model which is equipotent activity when compared with Atorvastatin. This might returned in addition to its own hypolipidemc activity to increased leptin sensitivity in hypothalamus. Further studies on Garlic needed to identify the possible mechanism of action on leptin.

\section{REFERENCES}

- Ansarullah RN, Jadeja MC, Patel TV, Ramachandran AV (2009): Antihyperlipidemic potential of a polyherbal preparation on Triton WR 1339. (Tyloxapol) induced hyperlipimia: A comparison with Lovastatin. International Journal of Green Pharmacy, p. 119-24.

- Arnault I, Auger J (2006): Seleno-compounds in garlic and onion. J Chromatogr A 1112:23 - 30.

- Brown GB, Xue-Qiao, Sacco DE, Alberts JJ (1993): Lipid lowering and plaque regression, New insights into prevention of plaque disruption and clinical events in coronary disease. Circulation, 87, 1781-91.

- Byrne DJ, Neil HA, Vallance DT, Winder AF (1999): A pilot study of garlic consumption shows no significant effect on markers of oxidation or sub-fraction composition of low-density lipoprotein including lipoprotein (a) after allowance for non-compliance and the placebo effect. Clin Chim Acta 285:1 - 33.

- Chen H (2005): Hyperlipidemia Health Encyclopedia-Diseases and Conditions., [Online].Available at: http://www.merck.com/mmpe /sec 12/ch159/ch159b.html. 
- Considine VR, Madhur KS, LHeiman LM, Aidas K, Stephens WT, Nyce RM et al (1996): Serum Immunoreactive-Leptin Concentrations in Normal-Weight and Obese Humans. N Engl J Med., 334 (5): 324-325.

- Davey Smith $G$ (1993): Cholesterol lowering and mortality the importance of considering initial level of risk. International journal of medicine, 306, 1367-1373.

- Drobiova H, Thomson M, Al-Qattan K, Peltonen-shalaby R, AlAmin $Z$ and Ali $M$ (2009): Garlic increases Antioxidant Levels in Diabetic and Hypertensive Rats determined by a Modified Peroxidase Method. Oxford Journals

- Frederickson DS, Lee RS (1965): A system for phenotyping hyperlipidemia. Circulation 31, p. 321-327.

- Friedewald WT, Levy RI, Friedrickson DS (1972): In: Tietz (Ed) Determination of LDL cholesterol. Text Book of clinical Biochemistry, New York, p.874-98.

- Ghatak A, Asthana OP (1995): Recent trends in hyperlipoproteinemias and its pharmacotherapy. Indian journal of Pharmacology, 27, 14-29.

- Gordon DJ, Probstifield JL, Garrision RJ, Neaton JD, Castelli WP, Knoke JD, Jacobs Jr., DR, Bangdiwala S and Tyroler HA (1989): High density lipoprotein cholesterol and cardiovascular disease, four prospective American studies, Circulation, 79, p. 8-15.

- Grundy SM (1986): Cholesterol and coronary heart disease a new era. Journal of American Medicine, 256 p. 2849-2858. 
- Hattori A, Yamada N, Nishikawa T, Fukuda H, Fujino T. (2001): Protective effect of ajoene on acetaminophen-induced hepatic injury in mice. Biosci. Biotechnol. Biochem., 65(11): 2555-2557.

- IlkerD, Mustafa K, Bilal A, Ashhan A, Erdinc D, Hanefi O, Hassan SO. (2004): Effect of garlic extract consumption on blood lipid and oxidant/antioxidant parameters in human with high blood cholesterol. J. Nutr. Biochem., 15 (6): 373-377.

- Isganaitis E, and Lustig HR (2005): Fast food, Central nervous system, Insulin resistance and Obesity. Arteriosclerosis, Thrombosis and Vascular Biology, 25, 2451.

- Joseph PK, Rao KR, Sundaresh CS. (1989): Toxic effects of garlic extract and garlic oil in rats. Indian J. Exp. Biol. 27(11): 977-979.

- Kaur SC (2006): Advances in biochemistry in health and disease., Biochemistry of Atherosclerosis. 16, p. 572.

- Kerckhoffs DAJM, Brouns F, Hornstra G, Mensink RP (2002): Effects on the human serum lipoprotein profile of beta-glucan, soy protein and isoflavones, plant sterols and stanols, garlic and tocotrienols. J Nutr 132:2494 - 2505S.

- Khosla P, Karan RS, Bhargava VK (2004): Effect of garlic oil on ethanol induced gastric ulcers in rats. Phytother Res 18:87 - 91.

- Lau BHS (2006): Suppression of LDL oxidation by garlic compounds is a possible mechanism of cardiovascular health benefit. J Nutr $136: 765 \mathrm{~S}-8 \mathrm{~S}$. 
- Lawson LD, Ransom DK, Hughes BG (1992): Inhibition of whole blood platelet aggregation by compounds in garlic glove extracts and commercial garlic products. Thromb Res 65:141- 56.

- Lee EJ, Kim KS, Jung HY, Kim DH, Jang HD (2005): Antioxidant activities of garlic (Allum sativum L.) with growing districts. Food Sci Biotechnol 14:123 - 30.

- Leelarungrayub N, Rattanapanone V, Chanarat N, Gebicki JM (2006): Quantitative evaluation of the antioxidant properties of garlic and shallot preparations. Nutrition 22:266- 74 .

- Liu C T, Sheen L Y and Lii C K (2007): Does garlic have a role as an antidiabetic agent? Mol. Nutr. Food Res, 51, 1353- 1364.

- Mahesar OH, Bhutto MA, Khand AA, Narejo NT (2010): Garlic used as an alternative medicine to control diabetic mellitus in alloxaninduced male rabbits. Pak J Physiol, 6 (1), 1- 6.

- Mcphee JS, Lingappa RV, and Ganong FW (2006): Pathophysiology of Disease: An Introduction To Clinical Medicine. 5th Edition. McGraw- Hill Publication, USA. Pages 552-556.

- Mohale DS, Dewani AP, Saoji AN, Khadse CD (2008): Antihyperlipidemic activity of isolated constituents from the fruits of Lagenaria siceraria in albino rats. I.J. of G. P., p. 104-07.

- Noaki M, Takeshi N, Mitsuyasu U, Nagatoshi I, Hidekatsu T and Minoru $\boldsymbol{H}$ (2007): Garlic as an antifatique agent. Mol. Nutr. Food Res., 51, 1329- 1334.

- Okada Y, Tanaka K, Fujita I, Sato E, Okajima H (2005): Antioxidant activity of thiosulfinates derived from garlic. Redox Rep 10: 96- 102. 
- Pierre S, Crosbie L, Duttaroy AK (2005): Inhibitory effect of aqueous extracts of some herbs on human platelet aggregation in vitro. Platelets 6:469- 73.

- Rahman K, Lowe GM (2006): Garlic and cardiovascular disease: a critical review. J Nutr 136:736S - 40S.

- Ramaa CS, Shirode AR, Mundada AS, Kadam VJ (2006): Nutraceuticals - an emerging era in the treatment and prevention of cardiovascular diseases. Curr Pharm Biotech 7:15 - 23.

- Slekovec M, Goessler W (2005): Accumulation of selenium in natural plants and selenium supplemented vegetable and selenium speciation by HPLC-ICPMS. Chem Speciat Bioavailab 17:63- 73.

- SPSS Inc. (2011): Statistical Package for the Social Sciences. Released 2011. IBM SPSS Statistics for Windows, Version 20.0. Armonk, NY: IBM Corp.

- Sukandar E, Permana H, Adyana IK et al (2010): Clinical Study of Turmeric (Curcuma longa L.) and Garlic Extracts as Antihyperglycemic and Antihyperlipidemic agent in Type-2 DiabetesDyslipidemia Patients. Science Alert.

- Sumioka I, Matsura T, Yamada K. (2001): Therapeutic effect of Sallylmercaptocysteine on acetaminophen-induced liver injury in mice. Eur. J. Pharmacol., 21 (2-3): 177-185.

- Velmurugan B, Nagini S (2005): Combination chemoprevention of experimental gastric carcinogenesis by s-allylcysteine and lycopene: modulatory effects on glutathione redox cycle antioxidants. J Med Food 8:494 - 501. 